\title{
Is the Corona pandemic a gateway to global surveillance?
}

For the first time in human
history, digital surveillance
technologies have allowed
governments around the world
to monitor almost everyone,
almost everywhere, almost all
the time. The public has largely
accepted such measures as
necessary in the fight against
the Coronavirus. But are we
right to passively accept the
abandonment of our right
to privacy - a fundamental
human right - because we
fear COVID-19 more? Regina
Surber of the University of
Zurich in Switzerland argues
that it's time to question the
legitimacy of the anti-pandemic
digital surveillance trend.

legitimacy of the anti-pand surveillance trend.

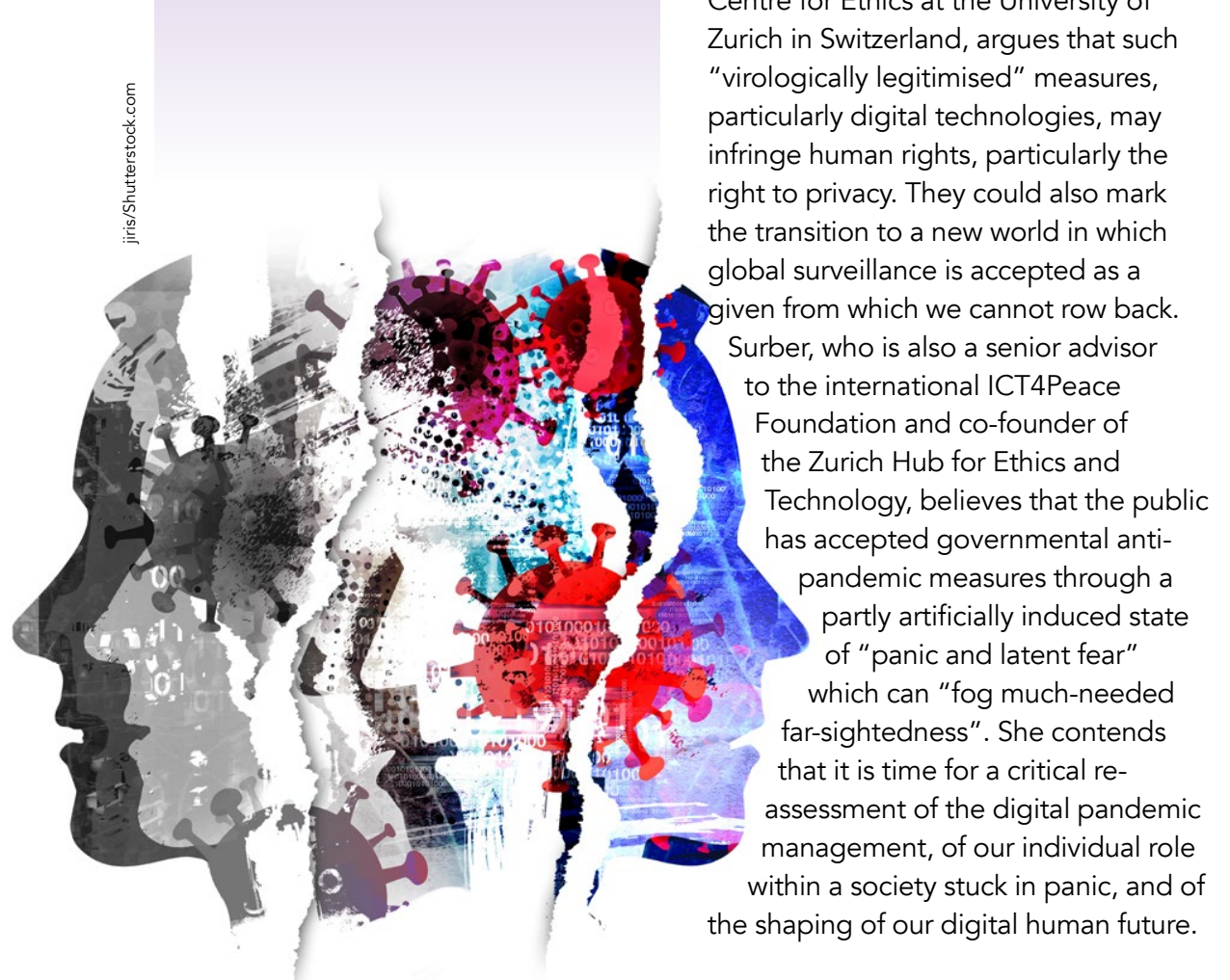

t was Nelson Mandela who said that IMPACT OF RESTRICTIONS "to deny people their human rights Approximately 70 countries around is to challenge their very humanity". What light does this verdict shed on the restrictions that the majority of people obal fight against the Coronavirus?

Lockdowns, travel restrictions, prohibitions against public assembly,
promotion of working from home, and national vaccine programmes have become the norm for billions of people. In addition, digital surveillance measures have featured heavily in the strategies that countries have adopted to fight the global pandemic.

he wold have adopted emergency restrictions and measures to contain recure public heath and of these restrictions may be thought of as infringing our human rights. For example, curfews and bans on gatherings may infringe freedom of movement and assembly, and the closing of schools and colleges restricts access to education. The move to online learning and healthcare may disadvantage those with no, or only limited, access to digital devices and the internet, and the shutting down of public life arguably threatens jobs and livelihoods and ultimately people's right to work.

These emergency measures can also ffect our mental health. Many people, particularly elderly people and those have to isolate from family and friends. In addition, despite the economic intervention of some governments, people's inability to work and changes in work patterns may lead to anxiety over lost or reduced incomes. General uncertainty about the virus and its origins, as well as unbalanced media coverage, may also increase public concern. Surber comments: "In attempting to secure public physical health, governmental restrictions may well be read as potentially putting public mental health in jeopardy.

GLOBAL SURVEILLANCE Perhaps the greatest threat is the threat to the right to privacy posed by the
emerging digital technologies that

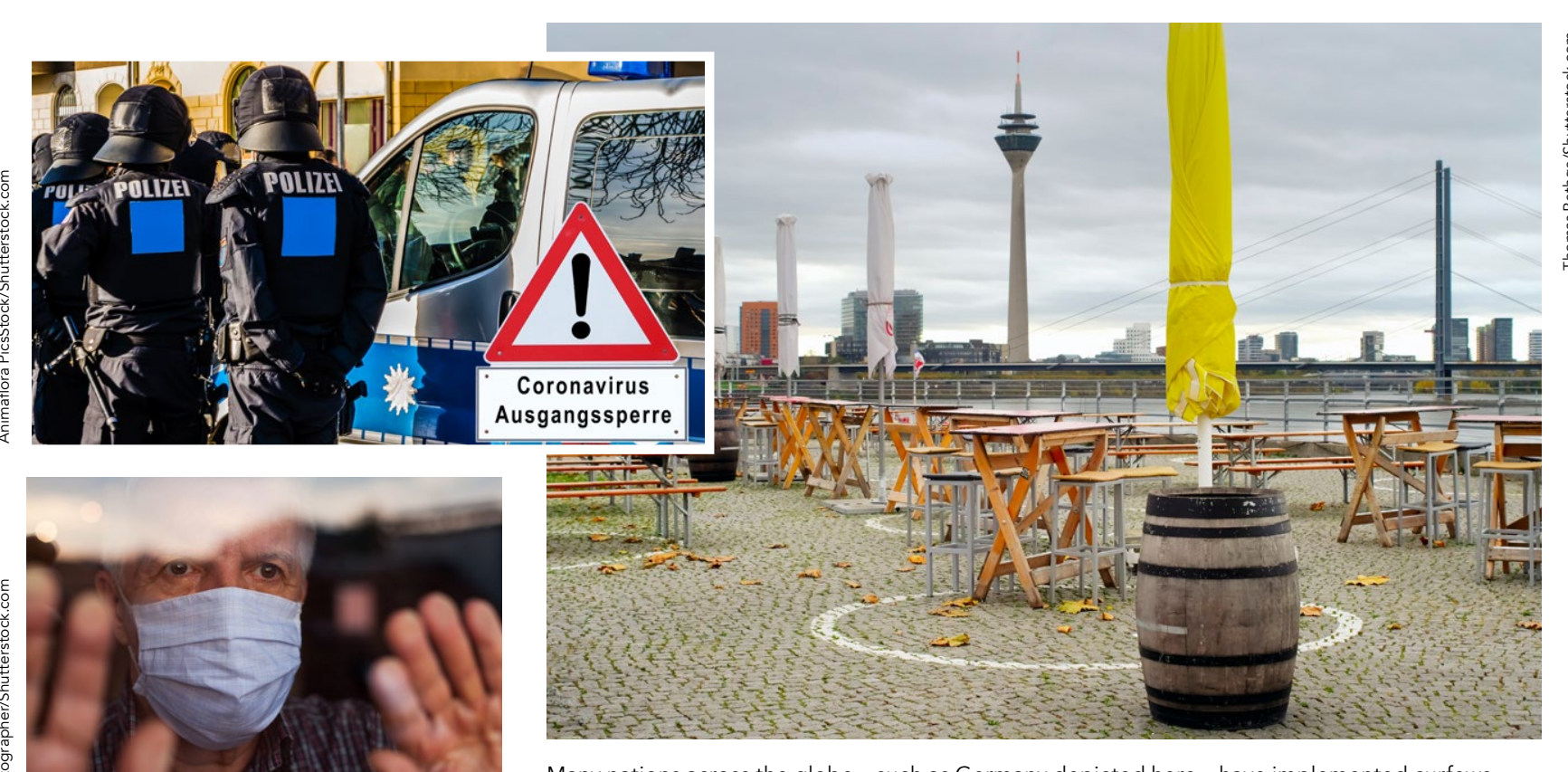

Many nations across the globe - such as Germany depicted here - have implemented curfews,
travel restrictions and the closing of public spaces in hopes to contain the spread of COVID-19.

In attempting to secure public physical health, governmental restrictions may well be read as potentially putting public mental health in jeopardy.

many governments have employed
in their fight against the pandemic. Primarily aimed at analysing the spread of the virus, monitoring curfews and travel restrictions, as well as monitoring people's vaccine status, Surber warns that these technologies may mark the surveillance reigns suprem

Surber divides the technologies into five groups: contact tracing apps, digital tracking, physical surveillance, Her latest, unpublished work also examines a sixth category: vaccine passport apps. For example, to date around 70 countries worldwide have employed contract tracing apps to alert individuals who have come into contact with someone who has the virus. Digital tracking, which makes use of aggregated mobile phone location data, has been used by some 38 governments. Physical surveillance, including the use of facial recognition software and surveillance drones, has been used by at least 27 countries. Some 18 governments disinformation about COVID-19 to justify censorship. Internet shutdowns have occurred in at least four countrie which track people's precise locations, are already in operation in 14 countries are in the pipeline. Not all the technologies employed protect people's privacy. However, surveillance without question, believing necessary part of the fight against the pandemic.

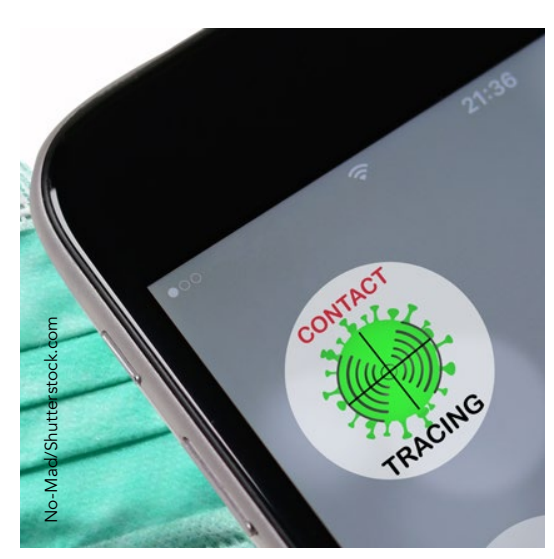

OLITICS AND PERMANENCE Surber argues that for restrictions governments should be able to that they are effective. However, with the new digital surveillance technologies, this is not always so. For example, they may depend on users having new mobile devices, which many do not, and some only work if functions are specifically enabled, which not Fryores to do. Surber cites France's contact tracing app, which people, even though in 2020 it was been sent.

Surber is also concerned that governments' emergency legislation should be "time-bound". She comments: "Unfortunately, crises have habit to fast-fonward certain processes

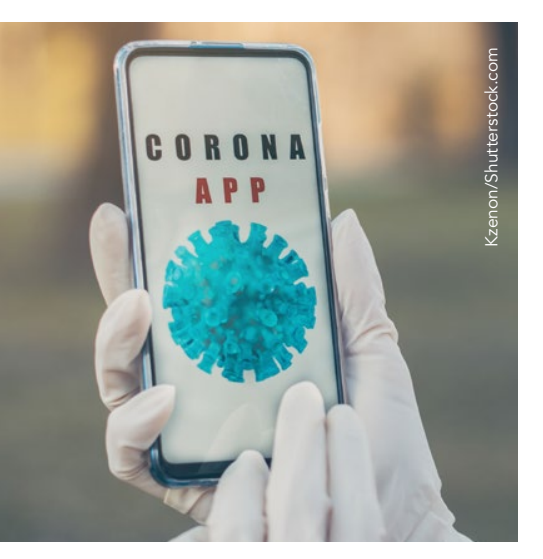
Finally, vaccine passport apps, some of are accompanied by policies to was downloaded by around 1.4 million 


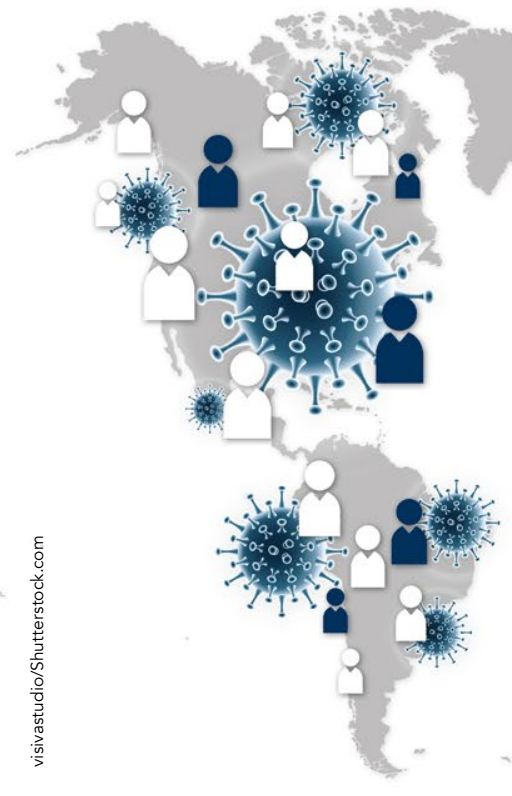

and instruments, whose consequences may not disappear once the crisis is over." Despite the fact that lockdown countries, surveillance technologies are still in place, and vaccine passport apps "continue the trend of ever-greater monitoring technologies".

The pandemic may also have led people to fear that even when it is over, anothe may take its place. Surber explain: "Pre-emptive fear may corroborate and consolidate national and global surveillance mechanisms and make us blind to our duty to question them." "Such fear has not been helped by the "unbalanced media coverage and to the starmism some have argued that the very future of humanity is at risk. Though experts initially estimated the overall lethality of the disease at approximately $10 \%$ the infection fatality rate has since been revised down to between 0.4 and $0.6 \%$. As a result, Surber argues that the evidence suggests that the existence of humanity is not under threat. However, she adds a warning: the emergency measures legislated by governments to combat the pandemic may put at risk the human rights that are "the very se of humanity

WHAT NEXT?

The pandemic may have resulted in the fact that for the first time in human history, digital surveillance technologies

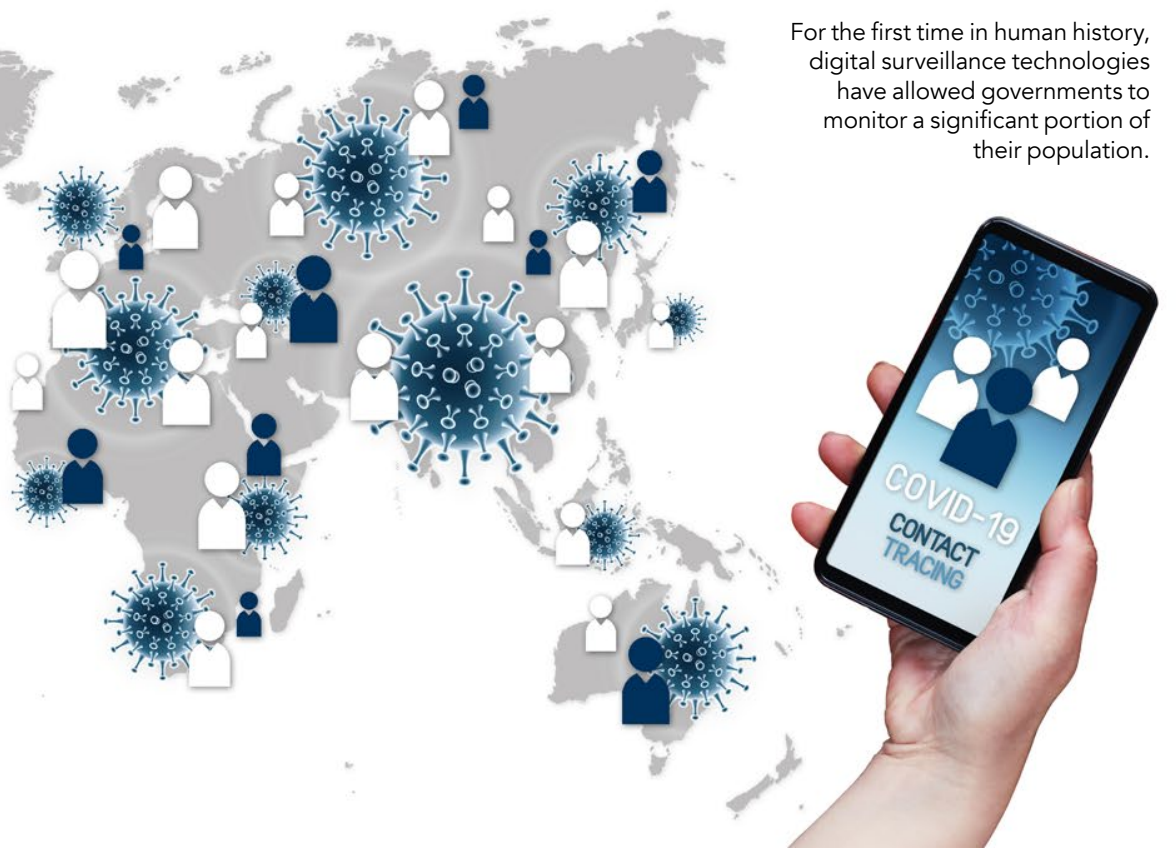

have allowed governments around the world to monitor "almost everyone,

to the infringement of human rights. She explains that it is a "civilian duty" o reflect on government measures

"global state of excessive emotionality" , Surber argues th

We must regard the 'biggest crisis of our generation' as an invitation for introspection, an increased level of selfunderstanding and self-empowerment.

powers of reflection and judgement. It is with individuals' power of judgement therefore up to us to ensure that, in the and reason. She comments: "Not only the pandemic, but also the panic and passive fearfulness"

Surber contends that we all have a part Similury to play in making sure that the measures facts in order to push glebal society used to fight the pandemic do not lead " back to reason". Governments must also

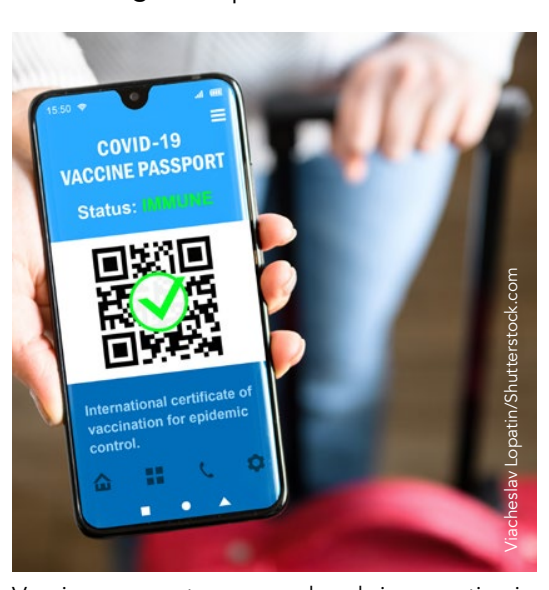

feck ensure that any anti-pandemic measure, including the approval of vaccines, is accompanied by science and is wherever possible "scientifically substantiated" and to individuals.

Surber argues that "it is not too late to pull the emergency break". She concludes. "We must regard the 'biggest crisis of our generation' as an invitation for introspection, for an increased
level of self-understanding and selfempowerment, and as a reminder that no one ever loses one's ability to choose."

14 countries

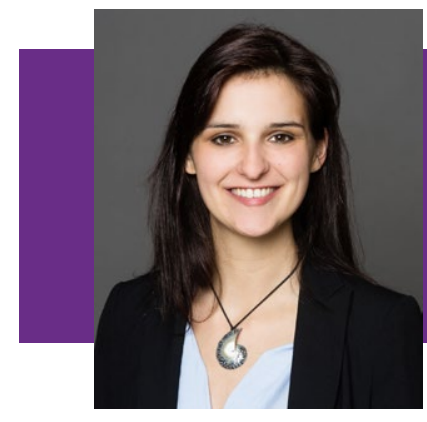

\section{Behind the Research} Regina Surber

E: regina.surber@uzh.ch T: +41446348540 W: uzh.academia.edu/ReginaSurber?from_ navbar=true W: philosophie. uzh.ch/de/seminar/people/research/politics cheneval/surber.html global panic lead to long-term "latent balance the costs and benefits to society,
Research Objectives

Surber reviews the digital surveillance measures that governments worldwide have adopted in their attempt to address the COVID-19 pandemic

\section{Detail}

Regina Sibylle Surber

Center for Ethics

University of Zurich
Zollikerstrasse 117

Zollikerstrasse 117

8008 Zurich

\section{Bio}

Regina Surber is a PhD candidate at the Center for Ethics at the University of Zurich, Switzerland, and Zurich Hub for Ethics and Techolognd Her dissert is a citique of modern ust war the Fo FTTAPeace, she analyses ethical, social, and political aspects of emerging technologies.

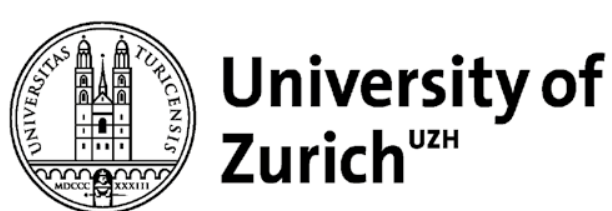

\section{References}

Surber, R.S. (2020). Corona pan(dem)ic: gateway to global surveillance. Ethics and Information Technology. Available at: https://doi.org/10.1007/s10676-020-09569-5

\section{Personal Response}

Is global surveillance using digital technologies inevitable?

II No. No conscious human creation is inevitable. What we choose to create we can also always choose
to un-create. What some have chosen to create, others can always choose to un-create. The 'capacity of choice' is key. The problem with the corona pan(dem)ic and its and lets us forget that we all have this capacity. It would be wise to act from this place of awareness, an not from a place of fear. This would allow us to calmly observe and evaluate what is truly happening behind the pandemic scene, and then actively choose what world a balancel and hund global future pus trengid responsibility on every one of us. II

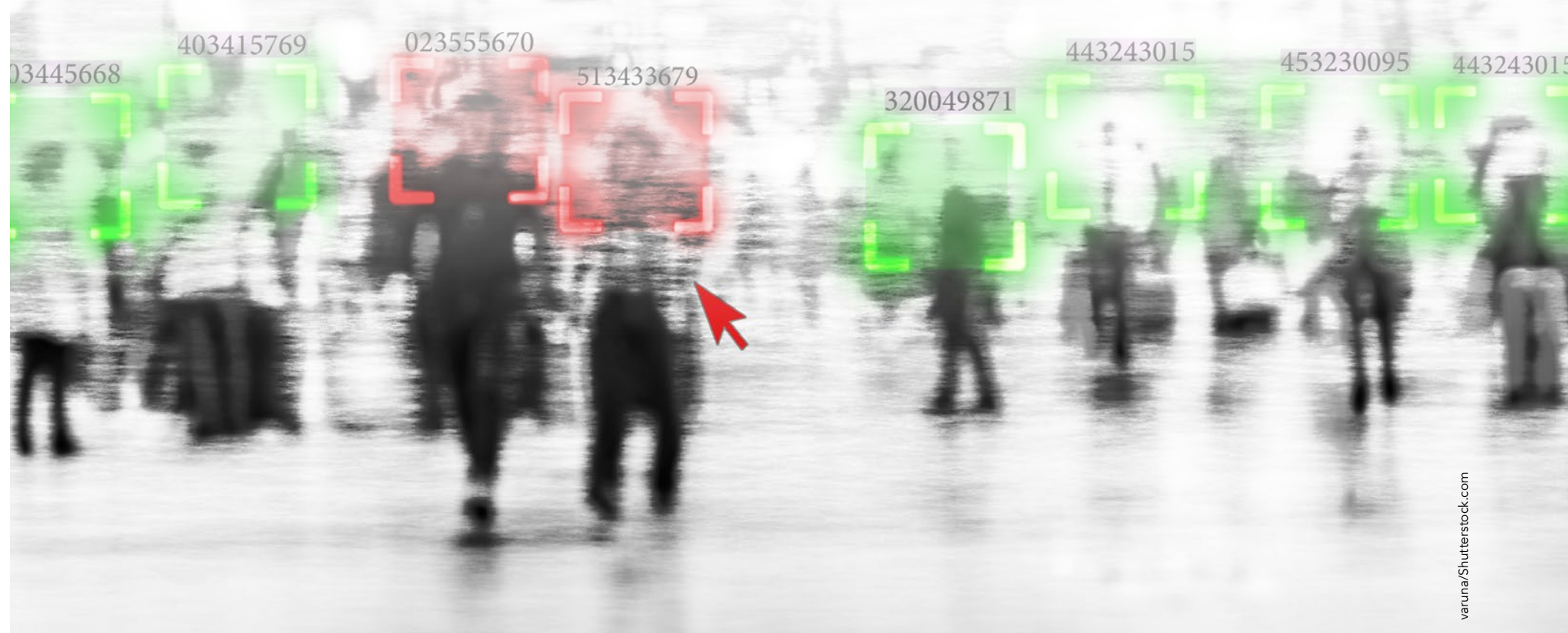

